\title{
SN-38 Acts as a Radiosensitizer for Colorectal Cancer by Inhibiting the Radiation-induced Up-regulation of HIF-1 $\alpha$
}

\author{
TAKAYUKI OKUNO, KAZUSHIGE KAWAI, KEISUKE HATA, KOJI MURONO, SHIGENOBU EMOTO, \\ MANABU KANEKO, KAZUHITO SASAKI, TAKESHI NISHIKAWA, TOSHIAKI TANAKA and HIROAKI NOZAWA \\ Department of Surgical Oncology, Faculty of Medicine, University of Tokyo, Tokyo, Japan
}

\begin{abstract}
Background/Aim: Hypoxia offers resistance to therapy in human solid tumors. The aim of the study was to investigate whether $\mathrm{SN}-38$, the active metabolite of irinotecan, acts as a radiosensitizer through inhibition of hypoxia-inducible factor (HIF)-1 $\alpha$ in the human colorectal cancer (CRC) cells. Materials and Methods: HT29 and SW480 cells were cultured with $\mathrm{SN}-38$ (0-4 $\mu \mathrm{M})$ immediately after irradiation (0-8 Gy). HIF-1 $\alpha$ expression was assessed using flow-cytometry and western blot analysis. Cell proliferation was evaluated by the calcein assay. Apoptosis and cell cycle were determined by flow-cytometry. Results: Radiation up-regulated HIF-1 $\alpha$, and SN-38 inhibited the radiation-induced HIF-1 $\alpha$. The combination of radiation and $S N-38$ inhibited cell proliferation more than radiation alone; treatment with $\mathrm{SN}-38$ after radiation exposure did not increase the number of apoptotic cells, whereas, it enhanced the $S$ and $G_{2} / M$ cell-cycle arrest and decreased the population of cells in $G_{1}$. Conclusion: $S N-38$ inhibits the radiation-induced up-regulation of HIF-1 $\alpha$ and acts as a radiosensitizer by inducing cell-cycle arrest in CRC cells.
\end{abstract}

It is estimated that 400,000 patients are diagnosed with rectal cancer in the world annualy $(1,2)$. Neoadjuvant chemoradiotherapy (CRT) is a standard treatment for patients with locally advanced rectal cancer which allows tumor reduction and decreases local recurrence $(3,4)$. However, only $15-20 \%$ of patients achieve a pathological complete response after CRT, $(5,6)$ which is associated with improved overall and recurrence free survival (7). Therefore, it is important to increase the response rate to CRT and identify

Correspondence to: Takayuki Okuno, Department of Surgical Oncology, University of Tokyo, 7-3-1 Hongo, Bunkyo-ku, Tokyo 113-0033, Japan. Tel: +81 338155411 (ext. 30347), Fax: +81 338116822, e-mail: okunotakayuki-tky@umin.net

Key Words: $\mathrm{SN}-38$, radiosensitizer, HIF-1 $\alpha$, colorectal cancer, cell cycle. novel chemotherapeutic regimens that improve the efficacy of this treatment.

Most solid tumors grow in a hypoxic environment, caused by the imbalance between the demand of oxygen by the proliferating tumor cells and the oxygen supply by the vascular tissue. Deprivation of oxygen induces the expression of hypoxia-inducible factor (HIF)- $1 \alpha$, a key molecule in hypoxia and ischemia (8). HIF-1 $\alpha$ influences tumor biology by regulating the expression of over 100 genes. HIF- $1 \alpha$ activation helps restore oxygen homeostasis by inducing angiogenesis through the up-regulation of vascular endothelial growth factor (VEGF) $(9,10)$ and anaerobic glycolysis (11). HIF- $1 \alpha$ also regulates apoptosis and cell cycle, (12) and induces autophagy (13), a cell survival mechanism in a hypoxic environment. Furthermore, HIF- $1 \alpha$ affects cancer progression: (14) up-regulation of HIF-1 $\alpha$ induces invasion and migration through epithelial-mesenchymal transition (EMT) $(15,16)$, and increases resistance to anti-cancer drugs (17). In the clinical setting, overexpression of HIF- $1 \alpha$ is associated with increased chemoresistance, mortality and metastasis in many human cancers $(18,19)$.

SN-38 is the active metabolite of irinotecan (CPT-11), a widely used chemotherapeutic drug for colorectal cancer (CRC). We previously found that the drug SN-38 overcomes chemoresistance in a hypoxic environment through the inhibition of HIF- $1 \alpha$ and has an anti-tumor effect in CRC cells (20). SN-38 inhibits DNA topoisomerase I, which is a nuclear enzyme important during DNA replication and transcription and inhibits DNA repair.

Recently, it has been shown that radiation up-regulates HIF- $1 \alpha$ in certain cancer cells. Specifically, radiation upregulates HIF-1 $\alpha$ through tumor reoxygenation in breast and prostate cancer cells $(21,22)$ and, in cervical cancer cells, the radiation-induced up-regulation of HIF- $1 \alpha$ induces angiogenesis (23). However, the association between radiation and HIF-1 $\alpha$ up-regulation in CRC cells has not been fully clarified.

Therefore, in this study, it was investigated whether radiation induces the up-regulation of HIF- $1 \alpha$ in CRC cells 
and whether SN-38 can inhibit this process. Furthermore, it was evaluated whether $\mathrm{SN}-38$ acts as a radiosensitizer through inhibition of radiation-induced HIF- $1 \alpha$ in CRC cells.

\section{Materials and Methods}

Cells and reagents. The human CRC cell lines HT29 and SW480 were obtained from the Japanese Cancer Research Resource Bank (National Institutes of Biomedical Innovation, Health and Nutrition, Ibaraki, Japan). The mutation status of the two cell lines was checked by RT-PCR in our institution (data not shown) and was as follows: HT29 (KRAS wild type, BRAF mutation, Phosphatidylinositol-4,5-Bisphosphate 3-Kinase Catalytic Subunit Alpha [PIK3CA] mutation, tumor protein p53 [TP53] mutation) and SW480 (KRAS mutation, BRAF wild type, PIK3CA wild type, TP53 mutation). Cells were cultured in RPMI-1640 medium supplemented with $5 \%$ fetal calf serum, $1 \%$ antibiotic/antimycotic and incubated in a $5 \% \mathrm{CO}_{2}$ incubator at $37^{\circ} \mathrm{C}$.

SN-38 (the active metabolite of CPT-11) was purchased from Toronto Research Chemicals (North York, Ontario, Canada). 5fluorouracil (5-FU), oxaliplatin, $\mathrm{CoCl}_{2}$, bovine serum albumin, and RPMI-1640 medium were purchased from Sigma-Aldrich (St. Louis, MO, USA). Fetal calf sera and antibiotic/antimycotic were purchased from Gibco BRL (Grand Island, NY, USA). Tetraacetoxymethyl ester (calcein-AM) was purchased from Dojindo Lab. (Kumamoto, Japan).

For flow-cytometry, the anti-HIF-1 $\alpha$ phycoerythrin (PE)conjugated antibody (Catalogue \# IC1935P) was purchased from R\&D systems (Minneapolis, MN, USA). FITC Annexin V Apoptosis Detection Kit and FITC BrdU Flow Kit were purchased from BD Pharmingen (San Diego, CA, USA). For western blot analysis, the anti-HIF-1 $\alpha$ antibody (ab2185), anti-GAPDH antibody (ab9485), and anti-VEGFA antibody (ab46154) were purchased from Abcam (Cambridge, MA, USA); the anti- $\beta$-actin antibody (Catalogue \# PM053) was purchased from MBL (Nagoya, Japan). The anti-Rabbit IgG-alkaline phosphatase (AP) antibody was purchased from Invitrogen Corp. (Carlsbad, CA, USA).

Cell treatment with radiation and/or anticancer agents. The radiation was given by an MBR-1505R2 X-ray generator (Hitachi Medical Co., Tokyo, Japan). Immediately after irradiation at a dose rate of $0.4 \mathrm{~Gy} / \mathrm{min}$ (total $0,1,2,4,8 \mathrm{~Gy}$ ), the cells were cultured with different concentrations of SN-38 $(0,0.25,1,4 \mu \mathrm{M}), 5-\mathrm{FU}(0$, $1.25,5,20 \mu \mathrm{M})$, or oxaliplatin $(0,1.25,5,20 \mu \mathrm{M})$ for $48 \mathrm{~h}$. Alternatively, the cells were treated with $150 \mu \mathrm{M}$ of $\mathrm{CoCl} 2$ for 24 $h$ as a positive control for the up-regulation of HIF-1 $\alpha$ (24).

Flow-cytometric analysis. HIF-1 $\alpha$ expression was assessed by flowcytometry as described previously (25), with small modifications. Briefly, after the above-described treatments, the cells were harvested, fixed with $4 \%$ paraformaldehyde in PBS, permeabilized with $0.1 \%$ Tween-20 in PBS, and stained using the anti-HIF-1 $\alpha$ PEconjugated antibody. The data relative to the expression of HIF-1 $\alpha$ in 10,000 cells were collected by flow-cytometry, using a Navios Flow Cytometer (Beckman Coulter, Brea, CA, USA), analyzed using the FlowJo software (Tree Star, Ashland, OR, USA), and expressed as the mean fluorescence intensity (MFI). All experiments were performed in triplicate, and the expression levels of HIF-1 $\alpha$ are presented as the mean $\pm \mathrm{SD}$.
Western blot analysis. Cells were harvested in Bolt LDS Sample Buffer and Bolt Sample Reducing Agent (Thermo Fisher Scientific, Waltham, MA, USA). After centrifugation at $15,300 \mathrm{~g}$ at $4^{\circ} \mathrm{C}$ for 10 min, the clear supernatant was collected and used for western blot analysis. Protein concentration was determined using the Qubit Protein Assay Kit (Thermo Fisher Scientific) according to the manufacturer's instructions. Equal amounts of proteins were denatured at $70^{\circ} \mathrm{C}$ for $10 \mathrm{~min}$, separated in Bolt 4-12\% Bis-Tris Plus gels (Thermo Fisher Scientific), then transferred onto PVDF membranes. The blotted membranes were incubated with the primary and secondary antibodies using the iBind Western System (Thermo Fisher Scientific), and immunoreactive bands were visualized using a Novex AP Rabbit Chemiluminescent Detection Kit (Thermo Fisher Scientific) according to the manufacturer's instructions. Images were analyzed with the ImageJ software (National Institute of Health, Bethesda, MD, USA). All experiments were performed in triplicate and the results are expressed as means $\pm \mathrm{SD}$.

Proliferation assay. Cells were plated at 5,000 cells per well in 96well plates, irradiated ( 0 or $4 \mathrm{~Gy})$ and treated with the relevant dose of SN-38 $(0,0.125,0.25,0.5,1,2,4 \mu \mathrm{M})$ for $48 \mathrm{~h}$. Subsequently, 1 $\mu \mathrm{M}$ of calcein-AM was added to each well. After incubation at $37^{\circ} \mathrm{C}$ for $30 \mathrm{~min}$, fluorescence intensity was measured with the Tera scan VP (Minerva Tech, Tokyo, Japan). All experiments were performed in triplicate, and cell viability is expressed as means \pm SD.

Detection of apoptosis by flow-cytometry. Cultured cells were stained with FITC-conjugated annexin $\mathrm{V}$ and propidium iodide (PI) for $5 \mathrm{~min}$ in the dark, using the FITC Annexin V Apoptosis Detection Kit according to the manufacturer's instructions. The number of annexin V-/PI- viable cells and annexin V+ apoptotic cells was evaluated by flow-cytometry. Simultaneously, apoptotic cells were counted by staining with trypan blue. All experiments were performed in triplicate, and the percentage of apoptotic cells is expressed as the mean $\pm \mathrm{SD}$.

Analysis of the cell cycle by flow-cytometry. The percentage of cells in each phase of the cell cycle was analyzed by flow-cytometry using the FITC BrdU Flow Kit, according to the manufacturer's instructions. Cultured cells were labeled with $1 \mathrm{mM}$ BrdU solution for $1 \mathrm{~h}$, and fixed and permeabilized with BD Cytofix/Cytoperm Buffer and BD Cytoperm Plus Buffer on ice. Subsequently, the cells were treated with $30 \mu \mathrm{g}$ of DNase for $1 \mathrm{~h}$. Finally, BrdU and total DNA were stained with a FITC-anti BrdU antibody and a 7-AAD solution in the dark and analyzed by flow cytometry. The experiments were performed three times, and the ratio of cells in the sub- $G_{0} / G_{1}, G_{0} / G_{1}, S$ and $G_{2} / M$ phases is expressed as the mean $\pm \mathrm{SD}$.

Statistical analysis. All experiments were repeated at least three times. Statistical significance of the differences was evaluated using the unpaired, two-tailed Student's $t$-test, and an association was considered significant when $p$ was less than 0.05 .

\section{Results}

Radiation up-regulates HIF-1 $\alpha$ in CRC cell lines. Firstly, it was investigated whether radiation regulates the expression of HIF-1 $\alpha$ in CRC cells. Flow cytometry revealed that HIF$1 \alpha$ was up-regulated in HT2 9 cells $48 \mathrm{~h}$ after exposure to 
a

Control

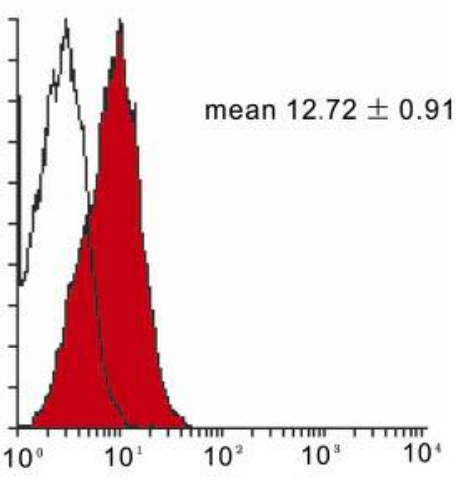

HIF-1 $\alpha$ expression

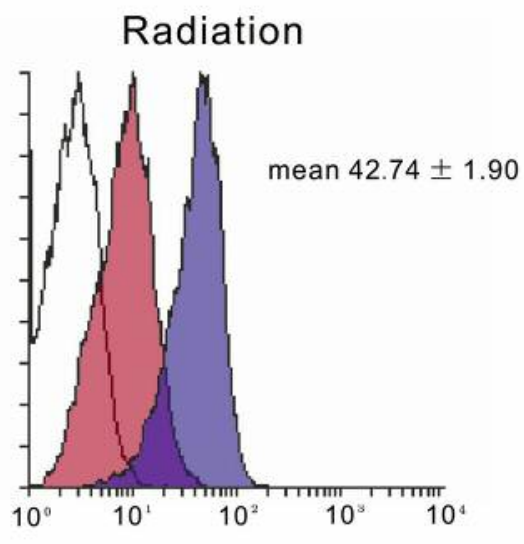

HIF-1 $\alpha$ expression

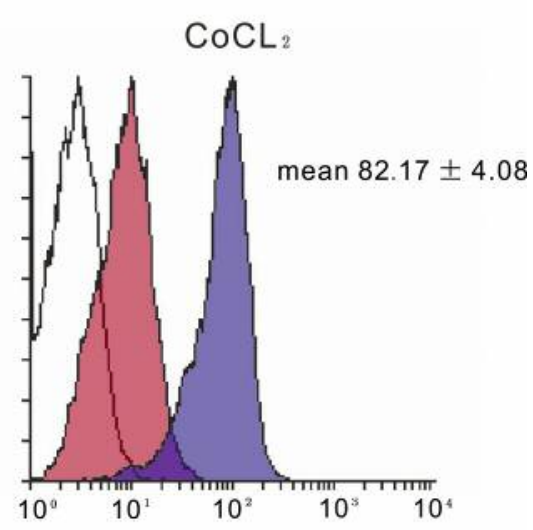

HIF-1 $\alpha$ expression b

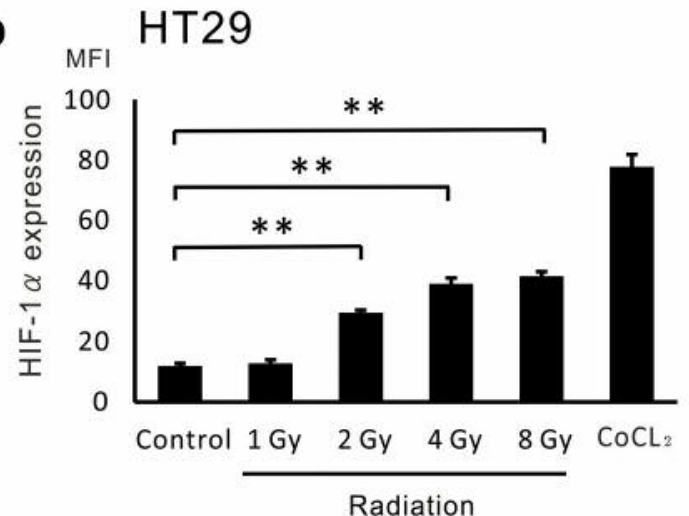

\section{$c_{\text {MFI }}$ SW480}

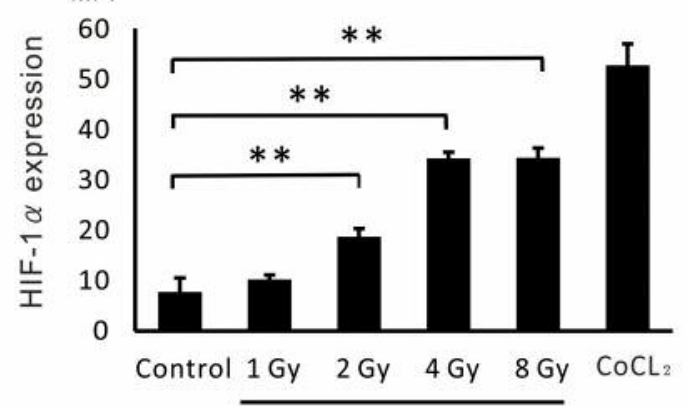

Radiation

Figure 1. Expression levels of hypoxia-inducible factor-1 $\alpha(H I F-1 \alpha) 48$ h after irradiation in colorectal cancer cells. $(A)$ Cultured cells were stained with an IgG phycoerythrin-conjugated (PE) antibody (negative control, white area) and with a HIF-1 $\alpha$ PE-conjugated antibody as control (red area). Radiation (4 Gy) induced the significant up-regulation of HIF-1 $\alpha$ in HT29 cells (blue area); treatment with $\mathrm{CoCl}_{2}$ was used as positive control (blue area). (B-E) Radiation (2-8 Gy) up-regulated HIF-1 $\alpha$ in HT29 and SW480 cells, as assessed by flow cytometry (B, C) and western blot analyses $(D, E)$. Values indicate the mean $\pm S D ; * p<0.05$, * $* 00.01$.

radiation (4 Gy, Figure 1A). Interestingly, radiation dosedependently up-regulated HIF- $1 \alpha$ in both HT29 and SW480 cells, and the levels of HIF-1 $\alpha$ following 4 or 8 Gy of radiation were almost the same. The levels of HIF-1 $\alpha$ following 4 Gy radiation were 3.5-fold and 5-fold higher in HT29 and SW480 cells, respectively, than those in control cells (Figure 1B and C).

The expression of HIF- $1 \alpha$ after radiation exposure was evaluated by western blot analysis. Exposure to radiation of 4 and 8 Gy up-regulated HIF- $1 \alpha$ in the two cell lines (Figure 1D). The levels of HIF- $1 \alpha$ following radiation (4 Gy) were 2-fold and 3-fold higher in HT29 and SW480 cells, respectively than those in control cells (Figure 1E).

Expression levels of HIF-la over time after radiation exposure. The expression of HIF- $1 \alpha$ over time, after

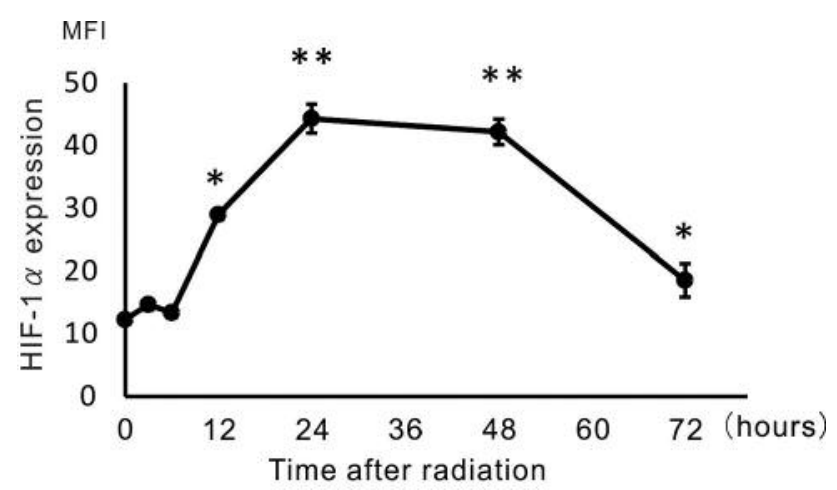

Figure 2. Levels of hypoxia-inducible factor-1 $\alpha(H I F-1 \alpha)$ at different times after radiation. The expression levels of $H I F-1 \alpha$, assessed by flow cytometry, were the highest $24-48$ h after radiation exposure. Values are the mean $\pm S D ; * p<0.05, * * p<0.01$. 
a

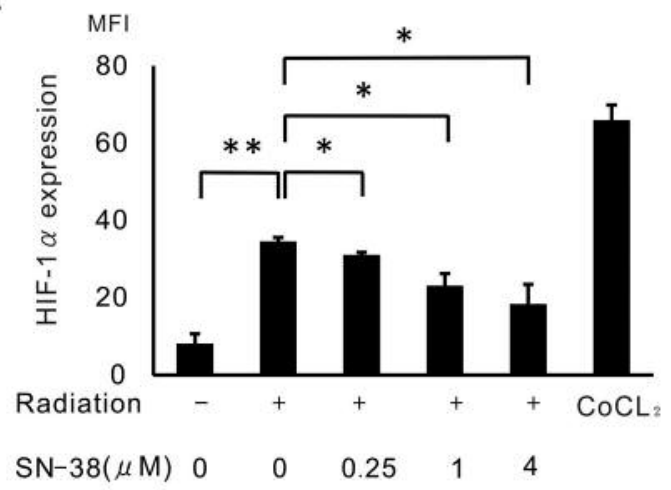

b

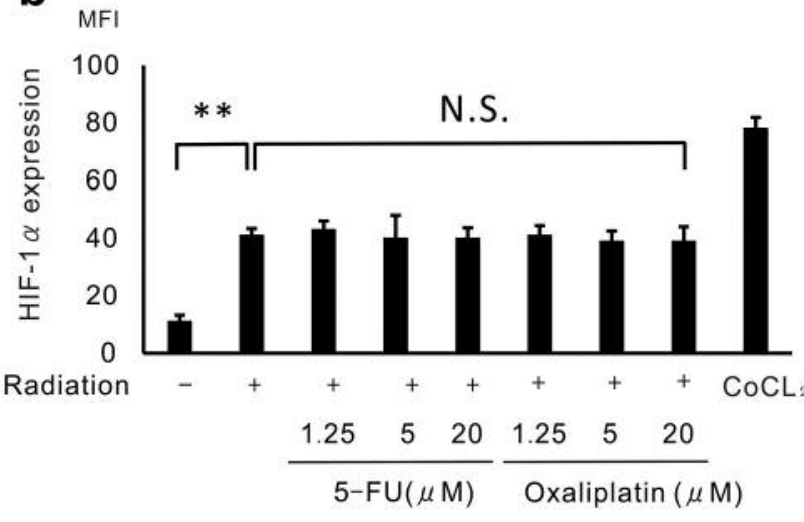

C
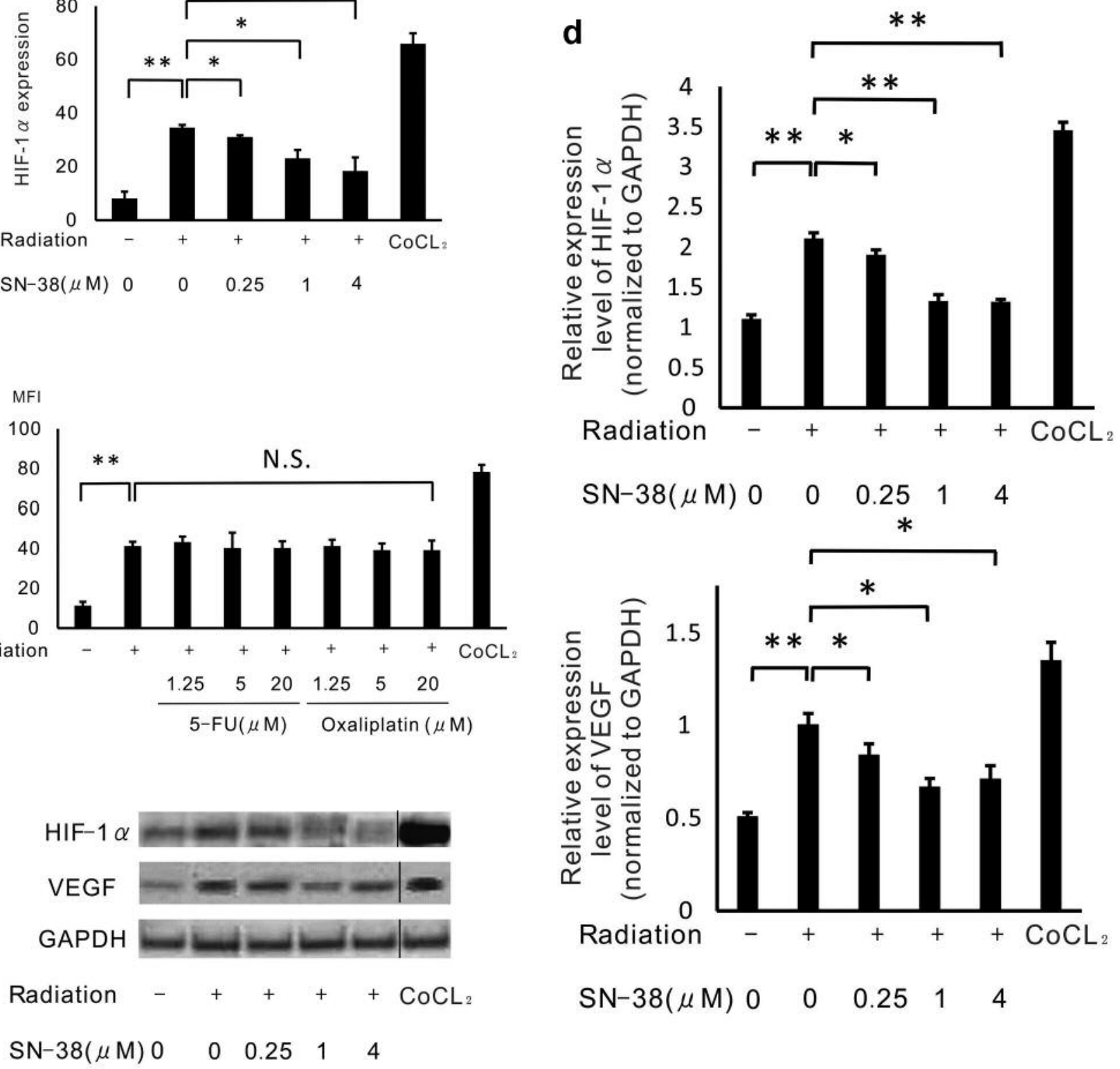

$\mathrm{SN}-38(\mu \mathrm{M}) 0 \quad 0 \quad 0.25 \quad 1 \quad 4$

Figure 3. Effect of SN-8 on radiation-induced up-regulation of hypoxia-inducible factor-1 a (HIF-1 $\alpha)$. (A) Expression levels of HIF-1 $\alpha$ in HT29 cells exposed to radiation (4 Gy) and treated with $S N-38$, 5-fluorouracil (5-FU) or oxaliplatin, evaluated by flow-cytometry. (B) SN-38 (0.25-4 $\mu M$ ) significantly inhibited the radiation-induced expression of HIF-1 $\alpha$, while 5-FU and oxaliplatin did not. (C, D) Effect of SN-38 on radiation-induced $H I F-1 \alpha$ and vascular endothelial growth factor (VEGF) expression by western blot analysis. Values are the mean $\pm S D ; * p<0.05$, **p<0.01. N.S.: Not significant.

exposure to radiation (4 Gy) was investigated by flowcytometry. In HT29 cells, HIF-1 $\alpha$ was up-regulated $12 \mathrm{~h}$ after irradiation, peaked $24-48 \mathrm{~h}$ post-radiation exposure, and almost reached pre-radiation exposure levels $72 \mathrm{~h}$ after exposure (Figure 2). Similar results were obtained in SW480 cells (data not shown).
$S N-38$ inhibits the radiation-induced up-regulation of HIF-1 $\alpha$. Treatment of HT29 cells with radiation was associated with up-regulation of HIF-1 $\alpha$ (Figure 3). However, treatment of the cells with increasing concentrations of SN-38 $(0.25-4 \mu \mathrm{M})$ $48 \mathrm{~h}$ after irradiation (4 Gy) resulted in a dose-dependent reduction of HIF- $1 \alpha$ levels (Figure 3A). Contrarily, treatment 

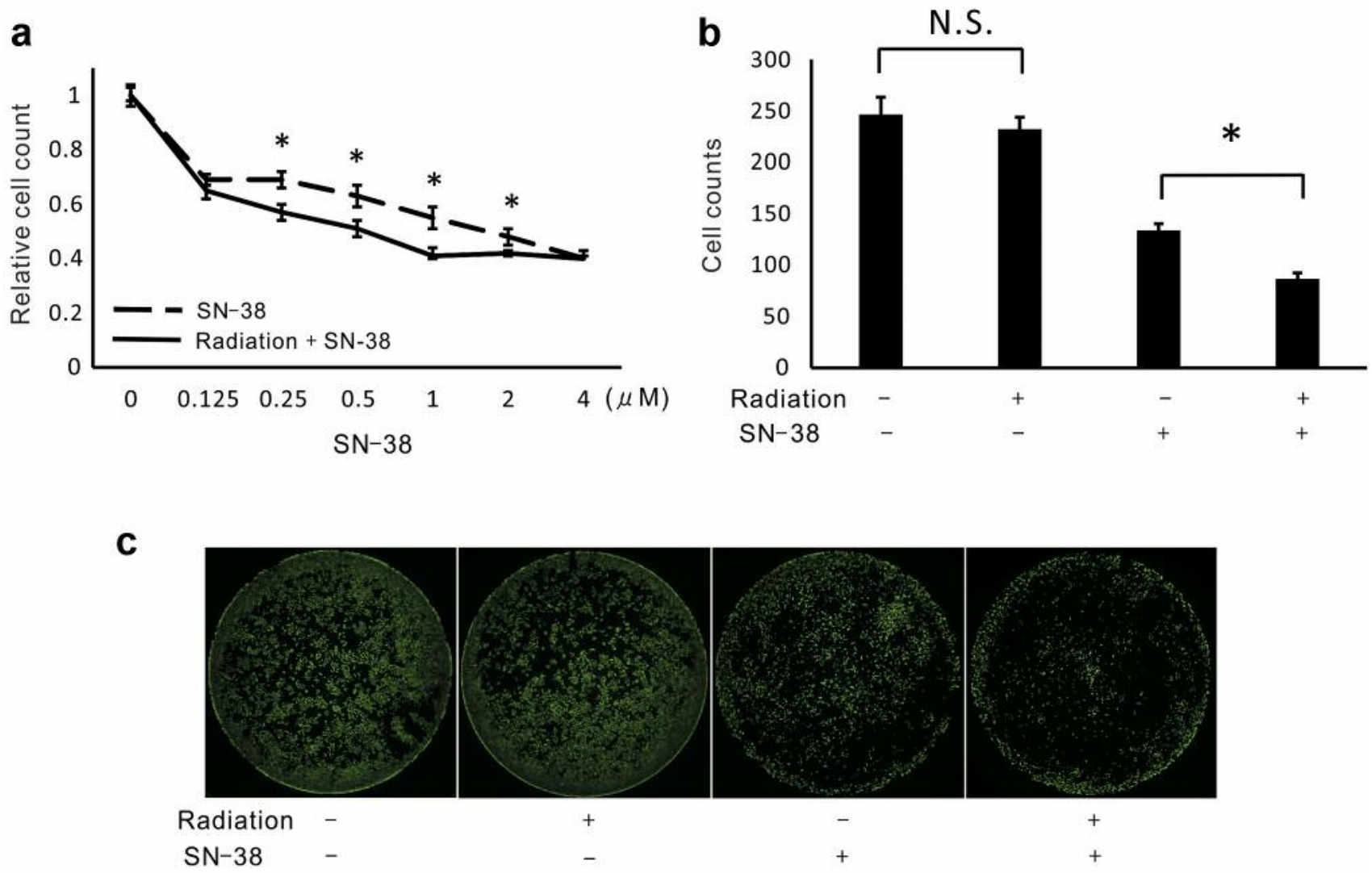

Figure 4. Cell counts after treatment by SN-38 with or without radiation. HT29 cells were treated with various concentrations of SN-38 (0-4 $\mu M$ ) for $48 \mathrm{~h}$ with or without radiation (4 Gy), and treatment effect was assessed by relative cell count. Relative cell count was calculated as the ratio to the values obtained with control cells after treatment with or without radiation for 48 , respectively. $0.25-2 \mu M$ of SN-38 significantly enhanced the treatment effect of radiation (A), which was most significant at $1 \mu M$ of $S N-38(B)$. Cell counts after each treatment were evaluated by calceinAM solution $(C)$. Values are given as the mean $\pm S D ; * p<0.05$. N.S.: Not significant.

with 5-FU and oxaliplatin did not inhibit the expression of radiation-induced HIF-1 $\alpha$ (Figure $3 \mathrm{~B})$.

The inhibitory effect of SN-38 on HIF-1 $\alpha$ expression was also evaluated by western blot. SN-38 (0.25-4 $\mu \mathrm{M})$ inhibited the expression of HIF- $1 \alpha$ induced by radiation and that of VEGF, which is induced by HIF- $1 \alpha$, and is the prototypical angiogenic cytokine in solid tumors (Figure 3C and D) (26). Similar results were obtained in SW480 cells (data not shown).

SN-38 enhances the effect of radiation in CRC cells. HT29 cells were treated with $\mathrm{SN}-38$, with or without radiation (4 Gy), and the effect of the treatment was assessed by measuring cell proliferation. Figure 4 shows that addition of SN-38 (0.25-2 $\mu \mathrm{M})$ significantly enhanced the effect of radiation in HT-29 cells (Figure 4a). The strongest effect was observed upon treatment with $1 \mu \mathrm{M}$ of SN-38. Specifically, at this concentration, the cell count in control and radiationexposed cells was similar (246 and 232, respectively); treatment with SN-38 induced a significant difference in the number of control vs. radiation-exposed cells (138 vs. 86, respectively, Figure 4B and C). Similar results were obtained in SW480 cells (data not shown).

Cotreatment with $\mathrm{SN}-38$ and radiation exposure does not enhance apoptosis. To investigate the mechanism through which SN-38 enhances the effect of radiation, apoptosis was investigated in cells treated with SN-38 (1 $\mu \mathrm{M})$ and radiation (4 Gy). The population of apoptotic HT29 cells (annexin V+/PI-) was similar in control and radiationexposed cells ( $1.3 \%$ vs. $0.5 \%$, respectively). Furthermore, cotreatment with $\mathrm{SN}-38$ and radiation exposure did not increase the percentage of apoptotic cells $(0.5 \%$ vs $.1 .4 \%$, respectively). Furthermore, the percentage of dead cells upon radiation exposure, measured by trypan blue staining, was not significantly different in SN-38 treated and untreated cells (Figure 5b). Similar results were obtained in SW480 cells (data not shown). 
a

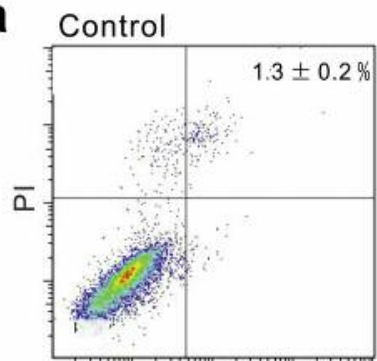

AnnexinV-FITC

Radiation

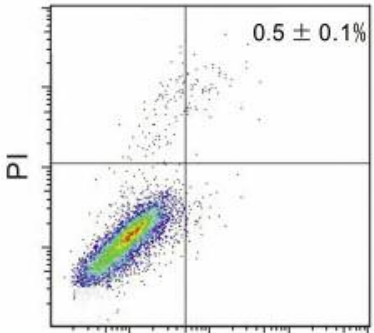

AnnexinV-FITC
$\mathrm{SN}-38$

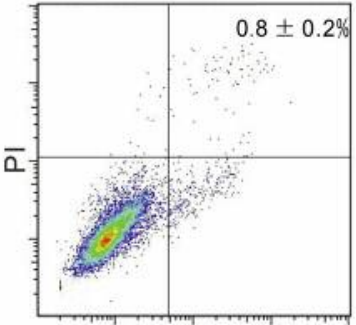

AnnexinV-FITC

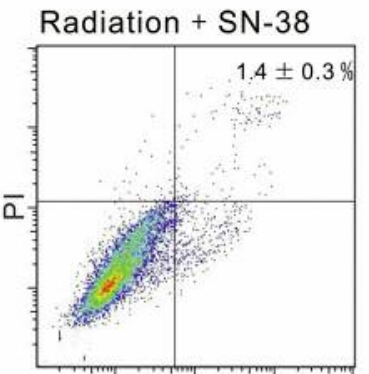

AnnexinV-FITC b

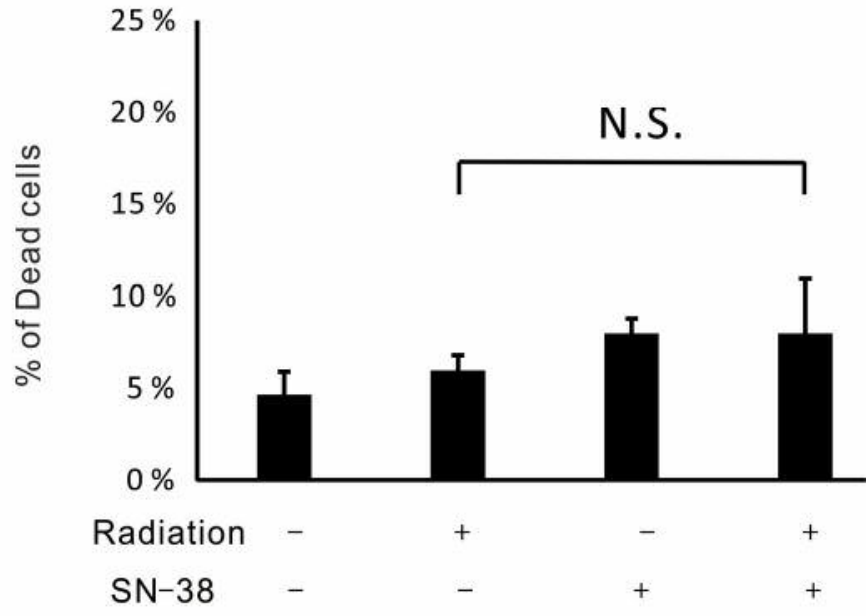

Figure 5. SN-38 does not affect apoptosis of cells exposed to radiation. (A) Apoptosis was evaluated by flow-cytometry using annexin V/FITC and propidium iodide (PI) staining of HT29 cells after each treatment (control, radiation [4 Gy], SN-38 [1 $\mu M$ ] and radiation [4 Gy] + SN-38 [1 $\mu M$ ]). Treatment with $\mathrm{SN}-38$ did not increase the number of apoptotic cells. (B) Similar results were obtained by Trypan blue staining of cells exposed to radiation and treated with $S N-38$. Values indicate the mean $\pm S D$. N.S.: Not significant.

Control

\section{G0/G1}

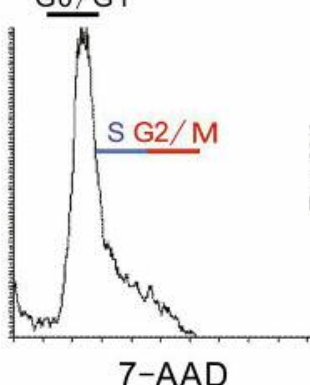

Radiation

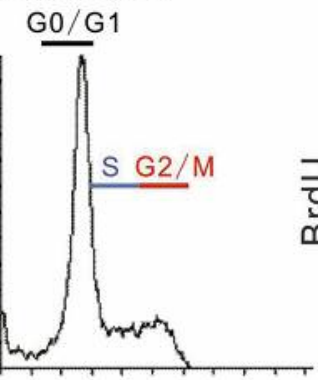

7-AAD

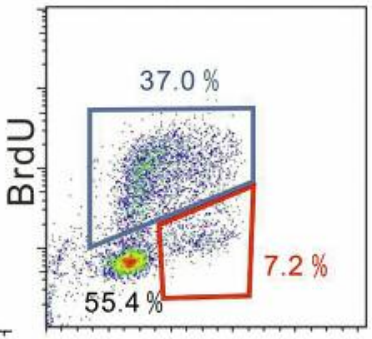

7-AAD

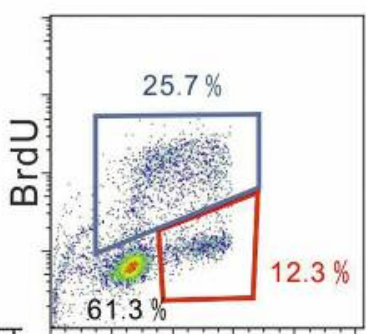

7-AAD

$\mathrm{SN}-38$

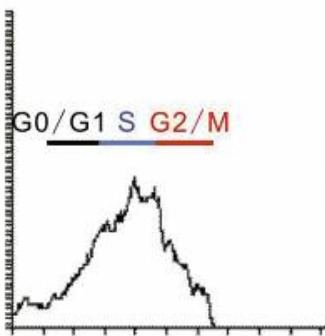

7-AAD

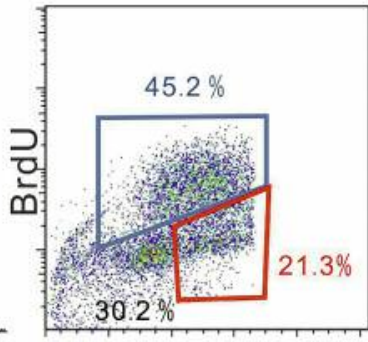

7-AAD

Radiation + SN-38

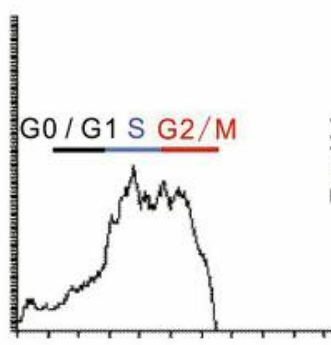

7-AAD

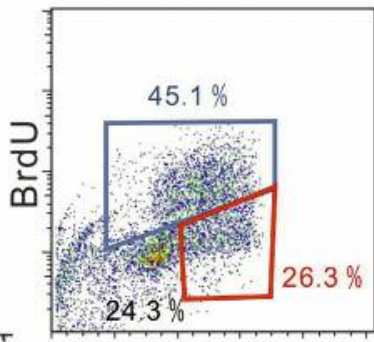

7-AAD

Figure 6. SN-38 affects the cell cycle of cells exposed to radiation. Cell cycle was evaluated by flow-cytometry using BrdU-FITC and 7-AAD staining of HT29 cells after each treatment (control, radiation [4 Gy], $S N-38$ [1 $\mu \mathrm{M}]$ and radiation [4 Gy] $+S N-38$ [1 $\mu M$ ]). Radiation induced $G_{2} / M$ phase (red-lined area) cell-cycle arrest, and $S N$-38 induced $S$ phase (blue-lined area) and $G_{2} / M$ phase cell-cycle arrest. Treatment with $S N$ - 38 after radiation exposure strongly enhanced $S$ and $G_{2} / M$ cell-cycle arrest and decreased the number of cells in $G 1$ (black-lined). Values are the mean $\pm S D$. 
Cotreatment with $S N-38$ and radiation exposure induces $S$ and $G_{2} / M$ phase cell cycle arrest. Radiation exposure (4 Gy) resulted in the arrest of cells in the $\mathrm{G}_{1}(55.4 \% v s .61 .3 \%$, control vs. radiation, respectively) and $\mathrm{G}_{2} / \mathrm{M}(7.2 \%$ vs. $12.3 \%$, control $v s$. radiation, respectively) phases of the cell cycle (Figure 6). Treatment with SN-38 $(1 \mu \mathrm{M})$ induced $\mathrm{S}$ and $\mathrm{G}_{2} / \mathrm{M}$ cell cycle arrest $(44.2 \%$ vs. $66.5 \%$, control vs. $\mathrm{SN}-38$, respectively). Furthermore, cotreatment with $\mathrm{SN}-38$ and radiation exposure strongly enhanced the arrest in the $\mathrm{S}$ and $\mathrm{G}_{2} / \mathrm{M}$ phases of the cell cycle $(44.2 \%$ vs. $71.4 \%$, control $v s$. radiation $+\mathrm{SN}-38$, respectively), and greatly decreased the population of cells in the G1 growth phase $(55.4 \% \mathrm{vs}$. $24.3 \%$, control vs. radiation $+\mathrm{SN}-38$, respectively) (Table I). Therefore, $\mathrm{SN}-38$ acts as a radiosensitizer through the $\mathrm{S}$ and $\mathrm{G}_{2} / \mathrm{M}$ phases of the cell cycle. Similar results were obtained in SW480 cells (data not shown).

\section{Discussion}

It was first examined whether radiation up-regulates HIF- $1 \alpha$ in human CRC cells (HT29 and SW480). Flow-cytometry and western blotting revealed that 2-8 Gy radiation dosedependently up-regulated HIF- $1 \alpha$. Regarding the timing of HIF-1 $\alpha$ expression, HIF- $1 \alpha$ levels increased $12 \mathrm{~h}$ after irradiation, peaked at 24-48 h, and then decreased. Moeller and colleagues also reported that radiation dose-dependently up-regulated HIF-1 $\alpha$, and the levels of expression peaked at $48 \mathrm{~h}$ after irradiation in breast cancer cells (21). With respect to dose of radiation, some studies indicate that 2-6 Gy radiation up-regulated HIF- $1 \alpha$ in head and neck squamous and endometroid cancer cells $(27,28)$, and 3-9 Gy radiation up-regulated HIF- $1 \alpha$ in lung adenocarcinoma cells; (29) these results are in agreement with our findings. Based on our results radiation up-regulated HIF- $1 \alpha$ even in CRC cells.

In a hypoxic environment, HIF- $1 \alpha$ activation induces angiogenesis through the up-regulation of $\operatorname{VEGF}(9,10)$ and anaerobic glycolysis, (11) and increases resistance to anticancer drugs (17). Our data show that radiation up-regulates VEGF, as well as HIF-1 $\alpha$, in CRC cells. These results suggest that radiation-induced HIF- $1 \alpha$ plays a role in cell survival upon radiation treatment as it does in a hypoxic environment.

In this study it was also investigated whether $\mathrm{SN}-38$, the active metabolite of CPT-11, inhibits the up-regulation of HIF- $1 \alpha$ induced by radiation. It was found that SN-38 inhibited radiation-induced HIF-1 $\alpha$ up-regulation in a dosedependent manner. Contrarily, 5-FU and oxaliplatin did not have the same effect. We have previously reported a similar effect of SN-38, which inhibited HIF-1 $\alpha$ up-regulation in a hypoxic environment (20). Here, the inhibition of the radiation-induced expression of HIF- $1 \alpha$ by $\mathrm{SN}-38$ was associated with the concomitant inhibition of VEGF, that is induced by HIF- $1 \alpha$. These dates suggest that SN-38 inhibits the effect of radiation-induced HIF- $1 \alpha$. In glioma cells, SN-
Table I. Cell-cycle analysis of treated cells.

\begin{tabular}{lcccr}
\hline & Sub- $_{0} / \mathrm{G}_{1}$ & $\mathrm{G}_{0} / \mathrm{G}_{1}$ & $\mathrm{~S}$ & \multicolumn{1}{c}{$\mathrm{G}_{2} / \mathrm{M}$} \\
\hline Control & $0.4 \pm 0.1$ & $55.4 \pm 2.1$ & $37.0 \pm 2.0$ & $7.2 \pm 0.2$ \\
Radiation & $0.7 \pm 0.2$ & $61.3 \pm 3.4$ & $25.7 \pm 2.1$ & $12.3 \pm 0.5$ \\
SN-38 & $3.3 \pm 1.0$ & $30.2 \pm 3.3$ & $45.2 \pm 2.9$ & $21.3 \pm 1.8$ \\
Radiation $+\mathrm{SN}-38$ & $4.1 \pm 0.8$ & $24.3 \pm 1.8$ & $45.1 \pm 2.2$ & $26.3 \pm 2.2$ \\
\hline
\end{tabular}

38 inhibits the translation of HIF- $1 \alpha$ mRNA (30), therefore reducing the levels of proteins whose expression is activated by HIF- $1 \alpha$ such as VEGF, matrix metalloproteinase-2 (MMP2), and Glut $1 / 3$ in a hypoxic environment $(31,32)$. It is suggested that $\mathrm{SN}-38$ inhibits the radiation-induced expression of HIF- $1 \alpha$ in a similar way.

Also, the effect of the inhibition of the radiation-induced expression of HIF-1 $\alpha$ by $\mathrm{SN}-38$ was examined on cell proliferation. As shown in Figure 4, 0.25-2 $\mu \mathrm{M}$ of SN-38 enhances the radiation-induced inhibition of cell proliferation, indicating that $\mathrm{SN}-38$ acts as a radiosensitizer. In CRC cells, treatment with 0.1-4 $\mu \mathrm{M}$ of SN-38 induces an anti-tumor effect under normal or hypoxic condition in vitro $(20,33)$. To reveal the mechanism through which SN-38 inhibits cell proliferation, flow-cytometry was used which showed that treatment with SN-38 to radiation did not affect apoptosis. Furthermore, cotreatment of cells with $\mathrm{SN}-38$ and radiation enhanced $\mathrm{S}$ and $\mathrm{G}_{2} / \mathrm{M}$ cell-cycle arrest, indicating that $\mathrm{SN}-38$ acts as a radiosensitizer by inducing cell cycle arrest. It has been reported that radiation induces $\mathrm{G}_{2} / \mathrm{M}$ cell-cycle arrest in hepatocellular carcinoma and cholangiocarcinoma cancer cells $(34,35)$ and $\mathrm{SN}-38$ induces $\mathrm{S}$ and $\mathrm{G}_{2} / \mathrm{M}$ cell cycle arrest in CRC cells $(36,37)$. In this study, treatment with $\mathrm{SN}-38$ potentiated the effects of radiation on the cell cycle and decreased the population of cells in the $\mathrm{G}_{1}$ phase, therefore inhibiting cell proliferation.

It has been reported that a ubiquitin-conjugating enzyme E2 inhibitor acts as a radiosensitizer through inhibiting HIF- $1 \alpha$, and RNA sequencing proved that ubiquitin-conjugating enzyme E2 inhibitor inhibited HIF-1 $\alpha$ pathway in both $T P-53$ wild and mutant CRC cells (HCT116, SW480) (38). It was also reported that suppression of HIF-1 $\alpha$ through RNA interference induces $\mathrm{G}_{2} / \mathrm{M}$ cell-cycle arrest in HCT 116 cells, (22) and suppression of radiation-induced HIF- $1 \alpha$ through other means induces $\mathrm{G}_{2} / \mathrm{M}$ cell-cycle arrest in lung adenocarcinoma cells (29). Though it cannot be excluded that SN-38 acts as a radiosensitizer through different pathways, it can be suggested that $\mathrm{SN}-38$ acts primarily through the inhibition of the radiation-induced expression of HIF- $1 \alpha$.

Recently, certain agents have been reported as radiosensitizers for CRC cells, though they have not been used in clinical settings, yet (39-42). SN-38 is the active metabolite 
of CPT-11, which is a widely used chemotherapeutic drug for patients with CRC. Some clinical trials have investigated the efficacy of a neoadjuvant CRT treatment including CPT-11 for rectal cancer and reported a pathological response rate as high as $25-35 \%(43,44)$. The efficacy of a CRT regimen including CPT-11 is expected. Our results support the effectiveness of a CRT regimen including CPT-11 in vitro, and a randomized trial of a CRT regimen including CPT-11 compared to that without CPT-11 is anticipated.

In conclusion, $\mathrm{SN}-38$ inhibits the radiation-induced upregulation of HIF- $1 \alpha$ and acts as a radiosensitizer by inducing $\mathrm{S}$ and $\mathrm{G}_{2} / \mathrm{M}$ cell-cycle arrest in CRC cells. Therefore, $\mathrm{SN}-38$ is an extremely promising drug to use in chemoradiotherapy treatments for rectal cancer.

\section{Conflicts of Interest}

The Authors have no conflicts of interest.

\section{Acknowledgements}

This research is supported by Grants-in-Aid for Scientific Research (C: grant number; 17K10620) from Japan Society for the promotion of Science. This research is supported by the Project for Cancer Research and Therapeutic Evolution (P-CREATE, grant number: JP17cm0106502) from the Japan Agency for Medical Research and Development (AMED).

\section{References}

1 Torre LA, Bray F, Siegel RL, Ferlay J, Lortet-Tieulent J and Jemal A: Global cancer statistics, 2012. CA Cancer J Clin 65: 87-108, 2015.

2 Siegel RL, Miller KD, Fedewa SA, Ahnen DJ, Meester RGS, Barzi A and Jemel A: Colorectal cancer statistics, 2017. CA Cancer J Clin 67: 177-193, 2017.

3 Sauer R, Becker H, Hohenberger W, Rodel C, Wittekind C, Fietkau R, Martus P, Tschmelitsch J, Hager E, Hess CF, Karstens JH, Liersch T, Schmidberger H and Raab R: Preoperative versus postoperative chemoradiotherapy for rectal cancer. N Engl J Med 351: 1731-1740, 2004.

4 Pucciarelli S, Toppan P, Friso ML, Russo V, Pasetto L, Urso E, Marino F, Ambrosi A and Lise M: Complete pathologic response following preoperative chemoradiation therapy for middle to lower rectal cancer is not a prognostic factor for a better outcome. Dis Colon Rectum 47: 1798-1807, 2004.

5 Rodel C, Martus P, Papadoupolos T, Fuzesi L, Klimpfinger M, Fietkau R, Liersch T, Hohenberger W, Raab R, Sauer R and Wittekind C: Prognostic significance of tumor regression after preoperative chemoradiotherapy for rectal cancer. J Clin Oncol 23: 8688-8696, 2005.

6 Valentini V, Coco C, Picciocchi A, Fuzesi L, Klimpfinger M, Fietkau R, Liersch T, Hohenberger W, Raab R, Sauer R and Wittekind C: Does downstaging predict improved outcome after preoperative chemoradiation for extraperitoneal locally advanced rectal cancer? A long-term analysis of 165 patients. Int J Radiat Oncol Biol Phys 53: 664-674, 2002.
7 de Campos-Lobato LF, Stocchi L, da Luz Moreira A, Geisler D, Dietz DW, Lavercy IC, Fazio VW and Kalady MF: Pathologic complete response after neoadjuvant treatment for rectal cancer decreases distant recurrence and could eradicate local recurrence. Ann Surg Oncol 18: 1590-1598, 2011.

8 Semenza GL and Wang GL: A nuclear factor induced by hypoxia via de novo protein synthesis binds to the human erythropoietin gene enhancer at a site required for transcriptional activation. Mol Cell Biol 12: 5447-5454, 1992.

9 Dor $\mathrm{Y}$ and Keshet E: Ischemia-driven angiogenesis. Trends Cardiovasc Med 7: 289-294, 1997.

10 Maxwell PH, Dachs GU, Gleadle JM, Nicholls LG, Harris AL, Stratford IJ, Hankinson O, Pugh CW and Ratcliffe PJ: Hypoxiainducible factor-1 modulates gene expression in solid tumors and influences both angiogenesis and tumor growth. Proc Natl Acad Sci USA 94: 8104-8109, 1997.

11 Denko NC: Hypoxia, HIF1 and glucose metabolism in the solid tumour. Nat Rev Cancer 8: 705-713, 2008.

12 Carmeliet P, Dor Y, Herbert JM, Fukumura D, Brusselmans K, Dewerchin M, Neeman M, Bono F, Abramovitch R, Maxwell P, Koch CJ, Ratcliffe P, Moons L, Jain RK, Collen D and Keshert E: Role of HIF-1alpha in hypoxia-mediated apoptosis, cell proliferation and tumour angiogenesis. Nature 394: 485-490, 1998.

13 Bellot G, Garcia-Medina R, Gounon P, Chiche J, Roux D, Pouyssegur $\mathbf{J}$ and Mazure NM: Hypoxia-induced autophagy is mediated through hypoxia-inducible factor induction of BNIP3 and BNIP3L via their BH3 domains. Mol Cell Biol 29: 25702581, 2009.

14 Semenza GL: Targeting HIF-1 for cancer therapy. Nat Rev Cancer 3: 721-732, 2003.

15 Hongo K, Tsuno NH, Kawai K, Sasaki K, Kaneko M, Hiyoshi M, Muruno K, Tada N, Nirei T, Sunami E, Takahashi K, Nagawa H, Kitayama $\mathbf{J}$ and Watanabe T: Hypoxia enhances colon cancer migration and invasion through promotion of epithelial-mesenchymal transition. J Surg Res 182: 75-84, 2013.

16 Gilkes DM, Semenza GL and Wirtz D: Hypoxia and the extracellular matrix: drivers of tumour metastasis. Nat Rev Cancer 14: 430-439, 2014.

17 Erler JT, Cawthorne CJ, Williams KJ, Koritzinsky M, Wouters BG, Wilson C, Miller C, Demonacos C, Stratford IJ and Dive C: Hypoxia-mediated down-regulation of Bid and Bax in tumors occurs via hypoxia-inducible factor 1-dependent and -independent mechanisms and contributes to drug resistance. Mol Cell Biol 24: 2875-2889, 2004.

18 Zhong H, De Marzo AM, Laughner E, Lim M, Hilton DA, Zagzag D, Buechier P, Issacs WB, Semenza GL and Simons JW: Overexpression of hypoxia-inducible factor 1alpha in common human cancers and their metastases. Cancer Res 59: 5830-5835, 1999.

19 Cao D, Hou M, Guan YS, Jiang M, Yang Y and Gou HF: Expression of HIF-1alpha and VEGF in colorectal cancer: association with clinical outcomes and prognostic implications. BMC cancer 9: 432, 2009.

20 Murono K, Tsuno NH, Kawai K, Sasaki K, Hongo K, Kaneko M, Hiyoshi M, Tada N, Nirei T, Sunami E, Takahashi K and Kitayama J: SN-38 overcomes chemoresistance of colorectal cancer cells induced by hypoxia, through HIF1alpha. Anticancer Res 32: 865-872, 2012. 
21 Moeller BJ, Cao Y, Li CY and Dewhirst MW: Radiation activates HIF-1 to regulate vascular radiosensitivity in tumors: role of reoxygenation, free radicals, and stress granules. Cancer Cell 5: 429-441, 2004.

22 Moeller BJ, Dreher MR, Rabbani ZN, Schroeder T, Cao Y, Li $\mathrm{CY}$ and Dewhirst MW: Pleiotropic effects of HIF-1 blockade on tumor radiosensitivity. Cancer Cell 8: 99-110, 2005.

23 Harada H, Kizaka-Kondoh S, Li G, Itasaka S, Shibuya K, Inoue $M$ and Hiraoka M: Significance of HIF-1-active cells in angiogenesis and radioresistance. Oncogene 26: 7508-7516, 2007.

24 Srinivasan S and Dunn JF: Stabilization of hypoxia-inducible factor-1alpha in buffer containing cobalt chloride for Western blot analysis. Anal Biochem 416: 120-122, 2011.

25 Kawai K, Tsuno NH, Kitayama J, Okaji Y, Yazawa K, Asakage M, Hori $\mathrm{N}$, Watanabe $\mathrm{T}$, Takahashi $\mathrm{K}$ and Nagawa $\mathrm{H}$ : Epigallocatechin gallate, the main component of tea polyphenol, binds to CD4 and interferes with gp120 binding. J Allergy Clin Immunol 112: 951-957, 2003.

26 Shing Y, Folkman J, Sullivan R, Butterfield C, Murray J and Klagsbrun M: Heparin affinity purification of a tumor-derived capillary endothelial cell growth factor. Science 223: 1296-1299, 1984.

$27 \mathrm{Lu} \mathrm{H}$, Liang K, Lu Y and Fan Z: The anti-EGFR antibody cetuximab sensitizes human head and neck squamous cell carcinoma cells to radiation in part through inhibiting radiationinduced up-regulation of HIF-1alpha. Cancer Lett 322: 78-85, 2012.

28 Miyasaka A, Oda K, Ikeda Y, Sone K, Fukuda T, Inaba K, Maki C, Enomoto A, Hosoya N, Tanikawa M, Uehara Y, Arimono T, Kuramoto H, Wada-Hiraike O, Miyagawa K, Yano T, Kawana $\mathrm{K}$, Osuga $\mathrm{Y}$ and Fujii $\mathrm{T}$ : $\mathrm{PI} 3 \mathrm{~K} / \mathrm{mTOR}$ pathway inhibition overcomes radioresistance via suppression of the HIF1alpha/VEGF pathway in endometrial cancer. Gynecol Oncol 138: 174-180, 2015.

29 Lai KG, Lin YH, Ho CT, Chen CY, Peng CY, Liu TZ and Chiou JF: Paclitaxel pretreatment overcomes hypoxia inducible factor1alpha-induced radioresistance acquisition of human hepatoma and lung adenocarcinoma cells. Life Sci 136: 7-12, 2015.

30 Rapisarda A, Uranchimeg B, Sordet O, Pommier Y, Shoemaker $\mathrm{RH}$ and Melillo G: Topoisomerase I-mediated inhibition of hypoxia-inducible factor 1: mechanism and therapeutic implications. Cancer Res 64: 1475-1482, 2004.

31 Sapra P, Zhao H, Mehlig M, Malaby J, Kraft P, Longley C, Greenberger LM and Horak ID: Novel delivery of SN38 markedly inhibits tumor growth in xenografts, including a camptothecin-11-refractory model. Clin Cancer Res 14: 18881896, 2008.

32 Kamiyama H, Takano S, Tsuboi K and Matsumura A: Antiangiogenic effects of SN38 (active metabolite of irinotecan): inhibition of hypoxia-inducible factor 1 alpha (HIF1alpha)/vascular endothelial growth factor (VEGF) expression of glioma and growth of endothelial cells. J Cancer Res Clin Oncol 131: 205-213, 2005.

33 Sasai K, Guo GZ, Shibuya K, Oya N, Shibata T, Nagata Y and Hiraoka M: Effects of SN-38 (an active metabolite of CPT-11) on responses of human and rodent cells to irradiation. Int $\mathrm{J}$ Radiat Oncol Biol Phys 42: 785-788, 1998.

34 Xue J, Zong Y, Li PD, Wang LX, Li YQ and Niu YF: Low-dose hyper-radiosensitivity in human hepatocellular HepG2 cells is associated with $\mathrm{Cdc} 25 \mathrm{C}$-mediated $\mathrm{G} 2 / \mathrm{M}$ cell cycle checkpoint control. Int J Radiat Biol 92: 543-547, 2016.
35 Hematulin A, Meethang S, Utapom K, Wongkham S and Sagan D: Etoposide radiosensitize p53-defective cholangiocarcinoma cell lines independent of their G2 checkpoint efficacies. Oncol Lett 15: 3895-3903, 2018.

36 Galvez-Peralta M, Dai NT, Loegering DA, Flatten KS, Safgren SL, Wagner JM, Karnitz LM and Kaufmann SH: Overcoming Sphase checkpoint-mediated resistance: sequence-dependent synergy of gemcitabine and 7-ethyl-10-hydroxycamptothecin (SN-38) in human carcinoma cell lines. Mol Pharmacol 74: 724$735,2008$.

37 Magrini R, Bhonde MR, Hanski ML, Notter M, Scherubi H, Boland CR, Zeitz M and Hanski C: Cellular effects of CPT-11 on colon carcinoma cells: dependence on p53 and hMLH1 status. Int J Cancer 101: 23-31, 2002.

38 Gombodori N, Yokobori T, Yoshiyama S, Kawabata-Iwakawa R, Rokudai S, Horikoshi I, Nishiyama M and Nakano T: Inhibition of ubiqutin-conjugating enzyme E2 may activate the degradation of Hypoxia-inducible factors and, thus, overcome cellular resistance to radiation in colorectal cancer. Anticancer Res 37: 2425-2436, 2017.

$39 \mathrm{Kim} \mathrm{EH}$, Lee H, Jeong YK and Jung WG: Mechanisms of SU5416, an inhibitor of vascular endothelial growth factor receptor, as a radiosensitizer for colon cancer cells. Oncol Rep 36: 763-770, 2016

40 Saberi A, Shahbazi-Gahrouei D, Abbasian M, Fesharaki M, Baharlouei A and Arab-Bafrani Z: Gold nanoparticles in combination with megavoltage radiation energy increased radiosensitization and apoptosis in colon cancer HT-29 cells. Int J Radiat Biol 93: 315-323, 2017.

41 Vijay M, Sivagami G, Thayalan K and Nalini N: Radiosensitizing potential of rutin against human colon adenocarcinoma HT-29 cells. Bratisl Lek Listy 117: 171-178, 2016.

42 Tian X, Nguyen M, Foote HP, Caster JM, Roche KC, Peters CG, Wu P, Jayaraman L, Garmey EG, Tepper JE, Eliasof S and Wang AZ: CRLX101, a nanoparticle-drug conjugate containing camptothecin, improves rectal cancer chemoradiotherapy by inhibiting DNA repair and HIF1alpha. Cancer Res 77: 112-122, 2017.

43 Jung M, Shin SJ, Koom WS, Jung I, Keum KC, Hur H, Min BS, Baik SH, Kim NK, Kim H, Lim JS, Hong SP, Kim TI, Roh JK, Park YS and Ahn JB: A Randomized Phase 2 Study of Neoadjuvant Chemoradiaton Therapy With 5-Fluorouracil/ Leucovorin or Irinotecan/S-1 in Patients With Locally Advanced Rectal Cancer. Int J Radiat Oncol Biol Phys 93: 1015-1022, 2015.

44 Sato T, Hayakawa K, Tomita N, Noda M, Kimukonya N, Watanabe T, Kato D, Sakai Y, Hiraoka M, Shimada M, Ikushima H, Baba H, Oya N, Oya M, Nemoto-Murofushi K, Takeuchi M and Watanabe M: A multicenter phase I study of preoperative chemoradiotherapy with S-1 and irinotecan for locally advanced lower rectal cancer (SAMRAI-1). Radiother Oncol 120: 222$227,2016$.
Received April 10, 2018

Revised May 5, 2018

Accepted May 7, 2018 